\title{
THYROID DYSFUNCTION IN PREGNANCY - A TERTIARY CARE CENTRE EXPERIENCE
}

\author{
Bajaj $\mathbf{S}^{1}$, Chawla $\mathbf{T}^{1}$, Gupta $\mathbf{P}^{1}$, Chaurasia $\mathbf{A}^{1}$, Mehrotra $\mathbf{R}^{1}$ \\ ${ }^{1}$ Department of Medicine, MLN Medical College, Allahabad.
}

\begin{abstract}
Introduction: Thyroid dysfunction has profound effect on both the mother and the fetus. This study was conducted in order to evaluate the thyroid function in pregnancy and its association with adverse maternal and fetal outcome.

Method: This was a cross sectional epidemiological study. 162 patients were recruited for the study and patients with chronic illnesses were excluded via a detailed history, examination and investigations. Thyroid function tests including anti thyroid peroxidase antibody levels were done to assess the thyroid status. Patients were categorized into subclinical hypothyroidism, overt hypothyroidism or hyperthyroid based on thyroid function test results. Maternal and fetal outcomes were ascertained and the association of outcomes with the thyroid dysfunction was assessed.

Results: 162 pregnant females irrespective of their gestational age were selected for the study. However, fetal and perinatal outcomes could be obtained in 138 cases. Prevalence of thyroid dysfunction among pregnant mothers was found to be $24.07 \%$ and subclinical hypothyroidism $(18.9 \%)$ was the commonest thyroid disorder. There was a clear relationship between thyroid dysfunction and history of abortion, pre-term delivery and stillbirths. Prevalence of low birth weight is significantly higher in mothers with thyroid dysfunction.

Conclusions: Thyroid dysfunction is common during pregnancy and subclinical hypothyroidism is the commonest thyroid disorder. Thyroid dysfunction has a clear association with poor fetal outcome with regards to abortions, pre-term delivery, still births and low birth weight.
\end{abstract}

Key-words: pregnancy, thyroid dysfunction, adverse pregnancy outcome, autoimmunity

\section{INTRODUCTION}

Thyroid dysfunction is a common problem in women of child-bearing age, which has an important implication in pregnancy and the puerperium for both mother and the baby. In the western population, the prevalence of hypothyroidism in pregnancy is around $2.5 \%$ (1), the prevalence of Graves' disease is around $0.1-0.4 \%$ (2) and that of thyroid autoimmunity (TAI) is around 5-10\% (3). Demand for thyroid hormones is increased during pregnancy, which may precipitate or worsen a previously unnoticed thyroid disorder. Pregnancy can increase the size of pre-existing thyroid nodules, trigger formation of new thyroid nodules and possibly increase the risk of developing multinodular goitre later in life (4).

Thyroid dysfunction in pregnancy leads to problems to both the mother and fetus. In pregnant women with hypothyroidism, a threefold increased risk of developing preeclampsia and a twofold increased risk of developing postpartum haemorrhage has been documented (5). Even mild maternal thyroid hormone deficiency may lead to neurodevelopment complications in the fetus as well as beyond pregnancy in the early life of the child $(6,7,8)$. Still, the overall lack of evidence precludes a recommendation for universal screening for thyroid disorder in all pregnant women.

The objective of this study was to clinically evaluate thyroid status in pregnancy and to check the association of thyroid dysfunction to the pregnancy outcome.

\section{METHOD}

This study was conducted at M.L.N. Medical College, Allahabad and its associated hospital SRN Hospital, Allahabad during a period from July 2013 to July 2014. All antenatal mothers $>18$ years of age attending Obstetrics and Gynaecology OPD or admitted to the Department of Obstetrics and Gynaecology were included in the study.

Detailed clinical history was taken, focusing on the obstetrics and menstrual history. Thorough physical examination was done giving emphasis on clinical evaluation of thyroid and obstetrical examination. Mothers with pre-existing thyroid dysfunction, renal, hepatic or any other chronic illness were excluded from 
the study. Haemoglobin level, liver function tests, urea, creatinine, electrolytes, fasting glucose levels, ultrasound scan of abdomen, FT3, FT4, TSH and Anti TPO Ab levels were assessed in all the selected patients.

Patients were followed up until delivery and the pregnancy and fetal outcomes were obtained. Subjects were classified according to their thyroid function test (TFT) results (Table 1). The fetal and pregnancy outcomes were compared between the mothers with thyroid dysfunction to those without thyroid dysfunction using ' $\mathrm{t}$ ' test and Chisquare test.

\section{RESULTS}

There were 162 pregnant mothers, irrespective of their gestational age, recruited for the study. Fetal and perinatal outcomes were obtained in 138 patients. 24 patients $(14.81 \%)$ were lost for follow up.

Prevalence of thyroid dysfunction among pregnant mothers was $24.07 \%$. Hypothyroidism was found to be more common than hyperthyroidism. Amongst the patients with thyroid dysfunction, subclinical hypothyroidism was the commonest thyroid disorder (Figure 1).

History of abortions were significantly higher (33.33\%) in mothers with thyroid dysfunction as compared to $(15.15 \%)$ in mothers without thyroid dysfunction $\left(\chi^{2}=4.650, \mathrm{p}=0.031\right)$ (Table 1). Poor pregnancy outcome in the form of preterm delivery, abortion and stillbirth was more common in mothers with thyroid dysfunction compared to mothers without thyroid dysfunction $\left(\chi^{2}=4.516, \mathrm{df}=4 . \mathrm{p}=0.03\right)($ Table 1$)$.

There was a clear association between the prevalence of birth weight among babies who were born with thyroid dysfunction. $28 \%$ of the mothers with thyroid dysfunction gave birth to low birth weight baby compared to $9.1 \%$ of the mothers with normal thyroid function $\left(\chi^{2}=4.650, \mathrm{df}=1\right.$ and $\left.\mathrm{p}=0.031\right)$ (Table 1$)$.

\section{Table 1: Fetal outcome in mothers with thyroid dysfunction and normal thyroid function}

\begin{tabular}{|ccc|}
\hline & $\begin{array}{c}\text { Mothers with } \\
\text { thyroid } \\
\text { dysfunction } \\
(\mathrm{n}=39)\end{array}$ & $\begin{array}{c}\text { Mothers } \\
\text { without } \\
\text { thyroid } \\
\text { dysfunction } \\
(\mathrm{n}=99)\end{array}$ \\
\hline $\begin{array}{c}\text { Previous history of } \\
\text { abortion }\end{array}$ & $\begin{array}{c}33.3 \% \\
(\mathrm{n}=13)\end{array}$ & $\begin{array}{c}15.15 \% \\
(\mathrm{n}=15)\end{array}$ \\
$\begin{array}{c}\text { Term delivery } \\
\text { Pre-term delivery }\end{array}$ & $\begin{array}{c}64.1 \% \\
(\mathrm{n}=25)\end{array}$ & $\begin{array}{c}88.9 \% \\
(\mathrm{n}=88)\end{array}$ \\
$\begin{array}{c}17.9 \% \\
(\mathrm{n}=7)\end{array}$ & $\begin{array}{l}6.06 \% \\
(\mathrm{n}=6)\end{array}$ \\
$\begin{array}{c}\text { Abortions \& still } \\
\text { births }\end{array}$ & $\begin{array}{c}17.9 \% \\
(\mathrm{n}=7)\end{array}$ & $\begin{array}{l}5.05 \% \\
(\mathrm{n}=5)\end{array}$ \\
\hline $\begin{array}{c}\text { Low birth weight } \\
\text { babies (1.5-2.5kg) }\end{array}$ & $\begin{array}{c}28.0 \% \\
(\mathrm{n}=7)\end{array}$ & $9.1 \%$ \\
& & $(\mathrm{n}=8)$ \\
\hline
\end{tabular}

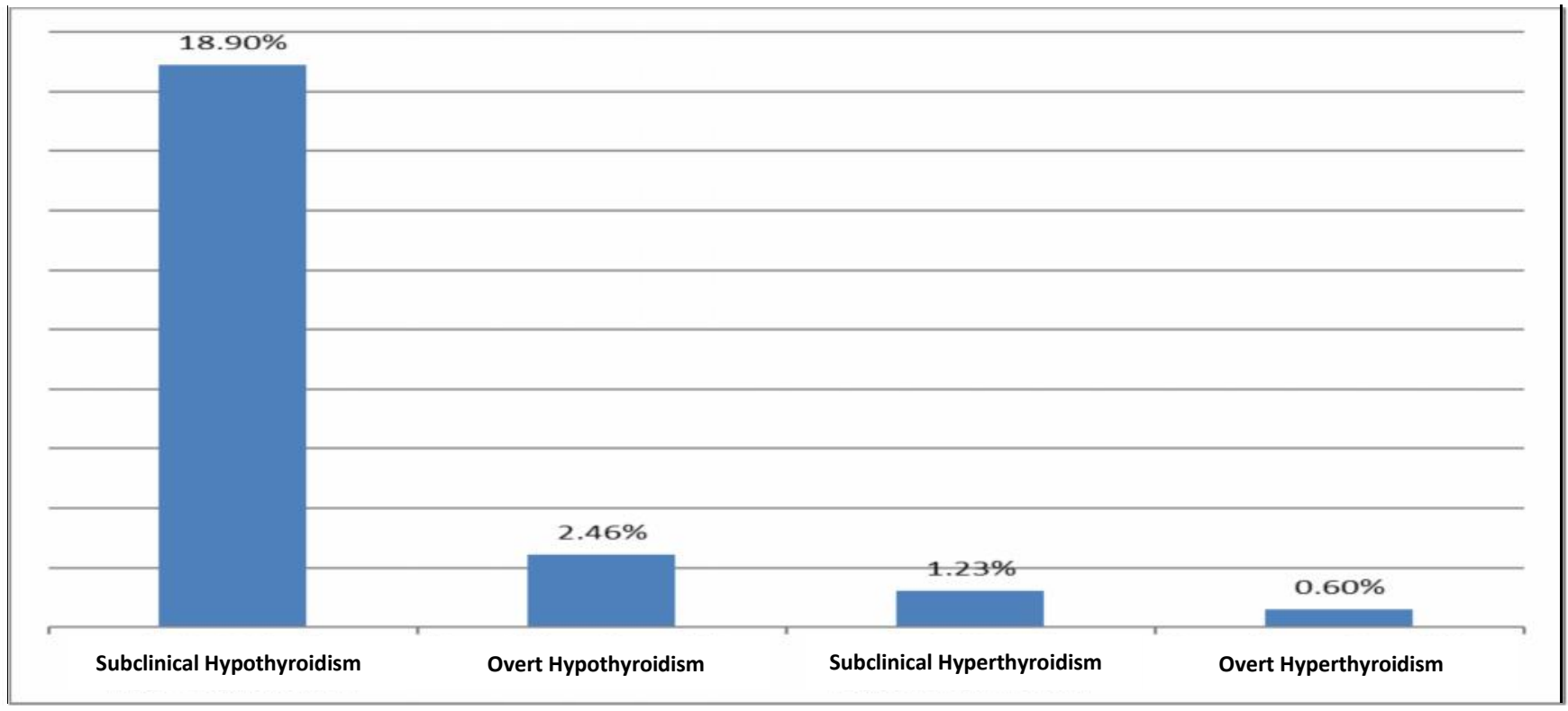

Figure 1: The categories of thyroid dysfunction during pregnancy 
Adverse fetal outcome was present in $85.7 \%$ of patients with positive autoimmune status $(\mathrm{p}<0.008)$ (Table 2). However, we did not find a significant association between pre-eclampsia and postpartum haemorrhage with thyroid dysfunction $(\mathrm{p}<0.907$ and $\mathrm{p}<0.487$ respectively).

\begin{tabular}{|c|c|c|}
\hline \multicolumn{3}{|c|}{$\begin{array}{l}\text { Table 2: Thyroid autoimmunity and } \\
\text { pregnancy outcome }\end{array}$} \\
\hline & $\begin{array}{l}\text { Adverse } \\
\text { pregnancy } \\
\text { outcome } \\
(\mathrm{n}=21)\end{array}$ & $\begin{array}{r}\text { Normal } \\
\text { delivery } \\
(n=18)\end{array}$ \\
\hline $\begin{array}{l}\text { Mothers with } \\
\text { raised TPO } \\
\text { antibody levels } \\
\quad(n=14)\end{array}$ & $\begin{array}{c}85.7 \% \\
(\mathrm{n}=12)\end{array}$ & $\begin{array}{l}14.2 \% \\
(n=2)\end{array}$ \\
\hline $\begin{array}{l}\text { Mothers with } \\
\text { normal TPO } \\
\text { antibody levels } \\
\quad(n=25)\end{array}$ & $\begin{array}{c}9.0 \% \\
(\mathrm{n}=36)\end{array}$ & $\begin{array}{l}64.0 \% \\
(n=16)\end{array}$ \\
\hline
\end{tabular}

\section{DISCUSSION}

Thyroid dysfunction is common and subclinical hypothyroidism is the commonest thyroid function disorder during pregnancy. History of abortions are higher and the pregnancy outcome in terms of premature delivery, abortions and still births are also higher in mothers with thyroid dysfunction. Prevalence of low birth weight deliveries is also higher among mothers with thyroid dysfunction. Thyroid autoimmunity has a clear association with adverse fetal outcome, and also with pre-eclampsia and post-partum haemorrhage.

Prevalence of thyroid dysfunction during pregnancy varies from $2.6 \%$ to $10 \%$ (9-14). However, some studies done in India, Dhanwal et al (15) and Ajmani et al (16) have reported higher prevalence of thyroid dysfunction in pregnancy $(14.5 \%$ and $12 \%$ respectively). The higher prevalence of iodine deficiency could have been the reason for these figures among pregnant mothers in India. However, this study demonstrated even higher prevalence of thyroid dysfunction among pregnant mothers and the higher prevalence of thyroid autoimmunity among this study population could have been the reason for this. Iodine supplementation with universal salt iodization has shown an increase in prevalence of thyroid autoimmunity in most of the populations. This highlights the need for a large multicentre study to cover the entire country in order to study this problem in this current context.
Thyroid dysfunction has deleterious effect to both the mother and fetus. Increased risk of miscarriage in the mothers with dysfunction is well known (17-22). Association of thyroid dysfunction with pre-term delivery, abortions and still births are also well described (16-23). There are very few studies which have not shown any effect on perinatal outcome and that also only in mothers of subclinical hypothyroidism (24). In this study, we observed a clear association of adverse pregnancy outcome with all the sub-categories of thyroid dysfunction.

Low birth weight is also a well-known adverse fetal outcome that is associated with both hypothyroidism and hyperthyroidism in pregnancy (25-28). Thyroid autoimmunity has also shown a clear association with low birth weight $(29,30)$. In this study we found that the incidence of low birth weight was increased 3 fold in the subjects with thyroid dysfunction, though the mean birth weight showed no significant difference between the group with thyroid dysfunction and those without. This association is further strengthened by the fact that we excluded the premature births from the data.

Hypertensive disease of pregnancy also shows a correlation with concentrations of TSH and endothelin, in parallel with the severity of hypertension (31). In this study, we failed to find any association of placental abruption and preeclampsia with thyroid dysfunction. This could be because of small sample size of the study.

There is a debate as to whether we should recommend universal screening of pregnant mothers for thyroid dysfunction (32, 33). The American Thyroid Association does not recommend universal thyroid screening during pregnancy and recommend aggressive case finding in specific subsets of subjects (34). However, the recent studies have shown that targeted case finding will miss around $30-50 \%$ cases of hypothyroidism and/or TAI $(35,36)$.

The results of the present study are in consensus with other studies validating the observation that thyroid dysfunction has profound effect on pregnancy as well as fetal outcomes. In addition to this, it also shows higher prevalence of thyroid dysfunction in South East Asian population compared to the western data, suggesting the necessity of recommending universal screening for thyroid dysfunction in pregnancy in order to improve the maternal and fetal outcome of these patients.

The cross sectional design of this study limits ability to assess the causality and was a major limitation of our study. Due to small sample size of the study, generalization of the findings was a problem. This is an area that needs further research to strengthen these findings and also find the reasons and answer to the questions that this study raises. 


\section{REFERENCES}

1. LeBeau SO, Mandel SJ. Thyroid disorders during pregnancy. Endocrinology Metabolism Clinics of North America. 2006; 35(1): 117-136.

2. Hollowell JG, Staehling NW, Flanders WD, Hannon WH, Gunter EW, Spencer CA et al. Serum TSH, T4, and thyroid antibodies in the United States population (1988 to 1994): National Health and Nutrition Examination Survey (NHANES III). Journal of Clinical Endocrinology and Metabolism. 2002; 87(2): 489-499.

3. Klein RZ, Haddow JE, Faix JD, Brown RS, Hermos RJ, Pulkkinen A et al. Prevalence of thyroid deficiency in pregnant women. Clinical Endocrinilogy (Oxford). 1991; 35: 41- 46.

4. Kung AWC, Chau MT, Lao TT, Tam SC, Low LC. The Effect of Pregnancy on Thyroid Nodule Formation. Journal of Clinical Endocrinology and Metabolism. 2002; 87(3): 1010-1014.

5. Kennedy RL, Malabu UH, Jarrod G, Nigam P, Kannan K, Rane A. Thyroid function and pregnancy: Before, during and beyond. Journal of Obstetrics and Gynaecology. 2010; 30(8): 774-783.

6. Victor J. Pop, Evelien P. Brouwers, Huib L. Vader, Thomas Vulsma, Anneloes L. Van Baar, Jan J. De Vijlder. Maternal hypothyroxinaemia during early pregnancy and subsequent child development: a 3year follow-up study. Clinical Endocrinology. 2003; 59(3): 282-288.

7. James E. Haddow, Glenn E. Palomaki, Walter C. Allan, Josephine R. Williams, George J. Knight, et al. Maternal Thyroid Deficiency during Pregnancy and Subsequent Neuropsychological Development of the Child. The New England Journal of Medicine. 1999; 341: 549-555.

8. Julvez Jordi, Alvarez-Pedrerol Mar, Rebagliato Marisa, Murcia Mario, Forns Joan, Garcia-Esteban Raquel, et al. Thyroxine Levels During Pregnancy in Healthy Women and Early Child Neurodevelopment. Epidemiology. 2013; 24(1): 150157.

9. Abalovich M, Gutierrez S, Alcarz G, Maccallini G, Garcia A, Levalle O. Overt and subclinical hypothyroidism complicating pregnancy. Thyroid. 2002; 12(1): 63-67.

10. Allan WC, Haddow JE, Palomaki GE, Williams JR, Mitchell ML, Hermos RL et al. Maternal thyroid deficiency and pregnancy complications: implications for population screening. Journal of Medical Screening. 2000; 7: 127-130.

11. Altomare M, La Vignera S, Asero P, Recupero D, Condorelli RA, Scollo P, et al. High prevalence of thyroid dysfunction in pregnant women. Journal of Endocrinological Investigation. 2013; 36(6): 407-411.

12. Glinoer D, Riahi M, Grun JP, Kinthaert J. Risk of subclinical hypothyroidism in pregnant women with asymptomatic autoimmune thyroid disorders. Journal of Clinical Endocrinology and Metabolism. 1994; 79: 197-204.

13. Moreno-Reyes R, Glinoer D, Van Oyen H, Vandevijvere S. High prevalence of thyroid disorders in pregnant women in a mildly iodinedeficient country: a population-based study. Journal of Clinical Endocrinology and Metabolism. 2013; 98(9): 3694-3701.
14. Pratt DE, Kaberlein G, Dudkiewicz A, Karande V, Gleicher N. The association of antithyroid antibodies in euthyroid nonpregnant women with recurrent first trimester abortions in the next pregnancy. Fertility and Sterility. 2000; 60(6): 10011005.

15. Dhanwal DK, Prasad S, Agarwal AK, Dixit V, Banerjee A K. High prevalence of subclinical hypothyroidism. Indian Journal of Endocrinology and Metabolism. 2013; 17: 281-284.

16. Ajmani SN, Aggarwal D, Bhatia P, Sharma M, Sarbhai V, Paul M. Prevalence of Overt and Subclinical Thyroid Dysfunction Among Pregnant Women and Its Effect on Maternal and Fetal Outcome. The Journal of Obstetrics and Gynecology of India. 2014; 64(2): 105-110.

17. Casey BM, Dashe JS, Well CE, McIntire DD, Byrd W, Leveno KJ et al. Subclinical hypothyroidism and pregnancy outcomes. Obstet Gynecol 2005; 105: 239245.

18. Nambiar V, Varsha S, Sarathi V, Lila AR, Menon PS, Shah NS et al. Prevalence and Impact of Thyroid Disorders on Maternal Outcome in AsianIndian Pregnant Women. Journal of Thyroid Research. 2011; 12: 115-119.

19. Wolfberg AJ, Lee-Parritz A, Peller AJ, Lieberman ES. Obstetric and neonatal outcomes associated with maternal hypothyroid disease. Journal of Maternal-Fetal \& Neonatal Medicine. 2005; 17: 35-38.

20. Haddow JE, Palomaki GE, Allan WC, Williams JR, Knight GJ, Gagnon J et al. Maternal thyroid deficiency during pregnancy and subsequent neuropsychological developments of the child. North England Journal of Medicine. 1999; 341:549-555.

21. Glinoer D, Fernandez-Soto ML, Bourdoux P, Lejeune B, Delange F, Lemone M et al. Pregnancy in patients with mild thyroid abnormalities: maternal and neonatal repercussions. Journal of Clinical Endocrinology and Metabolism. 1991; 73: 421427.

22. Stagnaro-Green A. Maternal thyroid disease and preterm delivery. Journal of Clinical Endocrinology and Metabolism. 2009; 94(1): 21-25.

23. Davis LE, Leveno KJ, Cunningham FG. Hypothyroidism complicating pregnancy. Obstet Gynaecol. 1988; 72(1): 108-112.

24. Cleary-Goldman J, Malone FD, Lambert-Messerlian G. Maternal thyroid hypofunction and pregnancy outcome. Obstet Gynaecol.. 2008; 112(1): 85-92.

25. Benhadi N, Wiersinga WM, Reitsma JB, Vrijkotte TGM and Bonsel GJ. Higher maternal TSH levels in pregnancy are associated with increased risk for miscarriage, fetal or neonatal death. European Journal of Endocrinology. 2009; 160: 985-991.

26. Patel J, Landers K, Li H, Mortimer RH, Richard K. Delivery of maternal thyroid hormones to the fetus. Trends in Endocrinology and Metabolism 2011; 22: 164170.

27. Stagnaro-Green A, Chen X, Bogden JD, Davies TF, Scholl TO. The thyroid and pregnancy: a novel risk factor for very preterm delivery. Thyroid. 2005; 15 : 351-357.

28. Leung AS, Millar LK, Koonings PP, Montoro M, Mestman JH. Perinatal outcome in hypothyroid 
pregnancies. Obstet Gynecol. 1993; 81: 349-353.

29. Männistö T, Vääräsmäki M, Pouta A, Hartikainen AL, Ruokonen A, Surcel HM et al. Perinatal outcome of children born to mothers with thyroid dysfunction or antibodies: a prospective population-based cohort study. Journal of Clinical Endocrinology and Metabolism. 2009; 94(3): 772-779.

30. Gayathri R, Lavanya S, Raghavan K. Subclinical Hypothyroidism and Autoimmune Thyroiditis in Pregnancy - A Study in South Indian Subjects .Journal Association Physicians India. 2009; 57: 691693.

31. Buimer M, Van Wassenaer AG, Ganzevoort W, Wolf H, Bleker OP, Kok JH et al. Transient hypothyroxinemia in severe hypertensive disorders of pregnancy. Obstet Gynecol. 2005; 106: 973-979.

32. Vaidya B, Hubalewska-Dydejczyk A, Laurberg P, Negro R, Vermiglio F, Poppe K. Treatment and screening of hypothyroidism in pregnancy: results of a European survey. European Journal of Endocrinology. 2012; 166: 49-54.

33. Abalovich M, Amino N, Barbour LA, Cobin RH, De Groot LJ, Glinoer D et al. Management of thyroid dysfunction during pregnancy and postpartum: an Endocrine Society Clinical Practice Guideline. Journal of Clinical Endocrinology and Metabolism. 2007; 92(8): S1-S47.

34. Stagnaro-Green A, Abalovich M, Alexander E, Azizi F, Mestman J, Negro R et al. Guidelines of the American Thyroid Association for the Diagnosis and Management of Thyroid Disease During Pregnancy and Postpartum. The American Thyroid Association Taskforce on Thyroid Disease During Pregnancy and Postpartum. 2011; 21: 1081 1125.

35. Thung SF, Funai EF, Grobman WA. The costeffectiveness of universal screening in pregnancy for subclinical hypothyroidism. American Journal of Obstet Gynecol. 2009; 200: 267.e1-267.

36. Dosiou C, Sanders GD, Araki SS, Crapo LM. Screening pregnant women for autoimmune thyroid disease: a cost-effectiveness analysis. European Journal of Endocrinology. 2008; 158: 841-851. 